MATEC Web of Conferences 25, 02012

(2015)

DOI: $10.1051 /$ matec conf/ 20152502012

(C) Owned by the authors, published by EDP Sciences, 2015

\title{
Study of Electrochemical Degradation of Bromophenol Blue at Boron-doped Diamond Electrode by Using Factorial Design Analysis
}

\author{
Fei Rong* \\ School of Biological Sciences and Medical Engineering, Southeast University, Nanjing, Jiangsu, China \\ Key Laboratory of Environmental Medicine Engineering of Ministry of Education, Southeast University, Nanjing \\ Jiangsu, China \\ Suzhou Key Laboratory of Environment and Biosafety, Suzhou, Jiangsu, China \\ Zhen Ding \\ Jiangsu Centers for Disease Control and Prevention, Nanjing, Jiangsu, China \\ Chunyong Zhang \\ Department of Chemistry, College of Science, Nanjing Agricultural University, Nanjing, Jiangsu, China \\ Jianjun Deng \\ Suzhou Dongqi Biological Technology Company Limited, Suzhou, Jiangsu, China
}

\begin{abstract}
As an ideal anode material, Boron-doped diamond (BDD) has been widely applied in electrochemical oxidation of various organic pollutants, for its unique physical and chemical properties. In this paper, the authors studied the degradation of bromophenol blue through the electrochemical anodic oxidation by using the boron-doped BDD as the anode. The effect of statistically important operating parameters on treatment performance, such as treatment time, flow rate, applied current and concentration of supporting electrolyte, was evaluated by employing a factorial design analysis in terms of color removal and COD removal amount. As a result, the BDD technology was approved to be highly effective in treating bromophenol blue. Moreover, the results revealed the applicability and potential of factorial design analysis in operating parameters optimization and practical engineering application of BDD technology.
\end{abstract}

Keywords: boron-doped diamond electrode; electrochemical degradation; bromophenol blue; factorial design analysis

\section{INTRODUCTION}

Bromophenol blue has been widely used for various industrial and research purposes, such as dye, $\mathrm{pH}$ indicator as well as color marker to monitor the process of agarose gel electrophoresis and polyacrylamide gel electrophoresis (Sarma \& Dutta 2006). Since it is labeled as being at a high toxicity level and persistence, many technologies, for example, adsorption (Salem 2000), photo-catalysis (Bouanimba et al. 2011), biotic and biochemical degradation(Ghaedi 2014) have been developed for the treatment of bromophenol blue. But these technologies have many disadvantages such as low efficiency, high cost and harsh operating conditions (Zhang et al. 2010). Thus the treatment of bromophenol blue justifies the search for new and improved technologies.

Advanced oxidation processes (AOPs) are widely-used techniques in wastewater treatment due to its strong oxidative ability and great efficiency. AOPs generate hydroxyl radical, the second strongest oxidants known after fluorine. It is able to react with organics giving dehydrogenated or hydroxylated de- rivatives, up to complete mineralization of organics (Vlyssides et al. 2000, Torres et al. 2007). One preferred AOP applied in organics degradation is electrochemical treatment, especially the anodic oxidation. The efficiency of anodic oxidation to some extent depends on the material of anode (Cañizares et al. 2005, Panizza et al. 2008).

The recent use of a BDD (boron-doped diamond) thin-film electrode in anodic oxidation has shown that it possesses technologically important characteristics such as an inert surface with low adsorption properties, remarkable corrosion stability and an extremely wide potential window in aqueous media (Fujishima et al. 2000, Szpyrkowicz et al. 2005). These properties make BDD electrode an ideal candidate for water treatment in the field of environmental electrochemistry (Brillas et al. 2005, Hmani et al. 2012).

This paper studied the degradation of bromophenol blue through the electrochemical anodic oxidation, using the BDD electrode, which has the excellent physicochemical properties, as the anode. The four parameters in the electrolysis including treatment time, flow rate, applied current and electrolyte concentration

*Corresponding author: rong@seu.edu.cn

This is an Open Access article distributed under the terms of the Creative Commons Attribution License 4.0, which permits unrestricted use, distribution, and reproduction in any medium, provided the original work is properly cited. 
on treatment efficiency were discussed, and a factorial design analysis was employed to evaluate the statistically importance of the operating parameters.

\section{EXPERIMENTAL}

\subsection{Materials and instruments}

Bromophenol blue and $\mathrm{Na}_{2} \mathrm{SO}_{4}$ were all commercial compounds from Alfa Aesar and used without further purification. The water employed in this study was from AVP-2-35G-01 Water-system (Millipore, USA). BDD electrode (boron-doped diamond thin film deposited on single crystal p-type Si wafer by MPCVD technology) was supplied by Kanagawa Academy of Science of Technology (KAST, Japan), with an effective surface area of $77.44 \mathrm{~cm}^{2}$. The same size stainless steel plate was supplied by Linai Manufacturing Factory (Zhuhai, China). The two electrodes were installed parallel to each other, keeping a $10 \mathrm{~mm}$ separation.

The concentrations of bromophenol blue after degradation were monitored by measuring absorbance decrease (at wavelength of $591 \mathrm{~nm}$ ), using a UV-spectrophotometer (UV-2450, Shimatzu, Japan). The color removal rate $(\eta)$ was calculated from the Equation 1 as follows:

$\eta=\frac{C_{0}-C_{t}}{C_{0}} \times 100 \%=\frac{A_{0}-A_{t}}{A_{0}} \times 100 \%$

Where $C_{t}$ corresponded to the concentration of bromophenol blue at time $t$ and $\mathrm{C}_{0}$ was its initial concentration. $A_{t}$ and $A_{0}$ were respectively the absorbance at time $t$ and its initial absorbance.

The COD values of the wastewater were analyzed through using a multifunctional water quality analyzer (Nova 60, Merck, Germany) in order to assess the treatment efficiency. The COD removal rate (CRR) was defined by the following Equation 2:

$$
C R R=\frac{\mathrm{COD}_{0}-\mathrm{COD}_{t}}{\mathrm{COD}_{0}} \times 100 \%
$$

Where, $\mathrm{COD}_{t}$ and $\mathrm{COD}_{0}$ were respectively the COD value at time $t$ and the initial COD value.

\subsection{Degradation experiments}

Degradation experiments were carried out in a batch one-compartment recirculation flow cell. Figure 1 presents a schematic representation of the complete apparatus employed. The bromophenol blue solution $(100 \mathrm{mg} / \mathrm{L})$ and electrolyte salts were introduced in a reservoir and continuously circulated with a peristaltic pump at a flow rate of $300-500 \mathrm{~mL} / \mathrm{min}$; its temperature is maintained at $20^{\circ} \mathrm{C}$ by a cooling water bath The processed volume was $200 \mathrm{~mL}$ in each run, and two parallel experiments were performed for each sample.

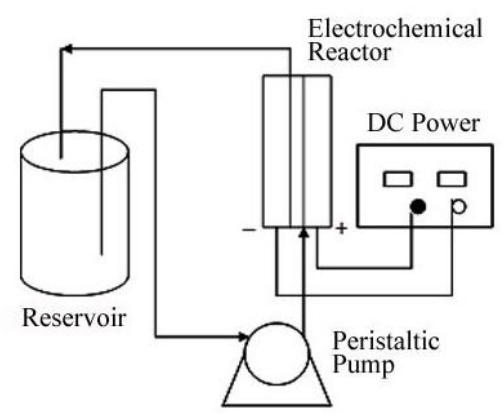

Figure 1. Schematic representation of the reactor for electrochemical degradation

\subsection{Experimental design and analysis}

Factorial design was implemented to evaluate the effect of the variables and their responses with least experiments (Otto 1998). A $2^{4}$ factorial design was employed to optimize the electrochemical degradation of bromophenol blue on BDD anode (Table 1). Four operating parameters including treatment time $\left(\mathrm{X}_{1}\right.$, min), flow rate $\left(X_{2}, \mathrm{~mL} / \mathrm{min}\right)$, applied current $\left(X_{3}, A\right)$ and electrolytes concentration $\left(\mathrm{X}_{4}, \mathrm{mmol} / \mathrm{L}\right)$ were applied as test factors to estimate the influence of the operating parameters on the treatment performance. And the factor levels were respectively selected + and - as the high level and the low level. The effects of four test factors on treatment performance were analyzed by means of the software package SPSS 17.0.

Table 1. Independent variables of the $2^{4}$ factorial design of experiment

\begin{tabular}{lllll}
\hline Level & $\mathrm{X}_{1}(\mathrm{~min})$ & $\mathrm{X}_{2}(\mathrm{~mL} / \mathrm{min})$ & $\mathrm{X}_{3}(\mathrm{~A})$ & $\mathrm{X}_{4}(\mathrm{mmol} / \mathrm{L})$ \\
\hline- & 20 & 300 & 0.30 & 3.0 \\
+ & 40 & 500 & 0.50 & 7.0 \\
\hline
\end{tabular}

\section{RESULTS AND DISCUSSIONS}

\subsection{Effect of test factors on color removal}

Table 2 presents the design matrix of the experiments generated by the software package SPSS 17.0. The degradation efficiency of bromophenol blue was investigated by a full $2^{4}$ experimental set containing 16 experiments. The concentration of bromophenol blue and corresponding color removal rate after degradation were also collected in Table 2 .

The average effects as well as the main and interaction effects were evaluated by using SPSS 17.0, and the color removal amount of bromophenol blue was chosen as response factors $Y_{1}$. The results were presented in Table 3, in which PSE (pseudo-standard error), ME (a margin of error) and SME (a simultaneous margin of error) were calculated by Lenth's method (Lenth 1989). 
Table 2. Design matrix of the $2^{4}$ factorial experimental design and results of color removal

\begin{tabular}{lllllll}
\hline Entry & $\mathrm{X}_{1}$ & $\mathrm{X}_{2}$ & $\mathrm{X}_{3}$ & $\mathrm{X}_{4}$ & $\begin{array}{l}\mathrm{C}_{t} \\
(\mathrm{mg} / \mathrm{L})\end{array}$ & $\begin{array}{l}\eta \\
(\%)\end{array}$ \\
\hline 1 & - & - & - & - & 25.14 & 74.6 \\
2 & + & - & - & - & 8.74 & 90.8 \\
3 & - & + & - & - & 21.98 & 76.0 \\
4 & + & + & - & - & 6.78 & 93.0 \\
5 & - & - & + & - & 11.8 & 87.0 \\
6 & + & - & + & - & 3.58 & 96.0 \\
7 & - & + & + & - & 12.32 & 86.0 \\
8 & + & + & + & - & 3.56 & 96.0 \\
9 & - & - & - & + & 23.56 & 72.9 \\
10 & + & - & - & + & 7.94 & 90.9 \\
11 & - & + & - & + & 24.29 & 74.2 \\
12 & + & + & - & + & 6.99 & 92.6 \\
13 & - & - & + & + & 14.31 & 83.5 \\
14 & + & - & + & + & 3.7 & 95.7 \\
15 & - & + & + & + & 14.62 & 84.7 \\
16 & + & + & + & + & 3.18 & 96.7 \\
\hline
\end{tabular}

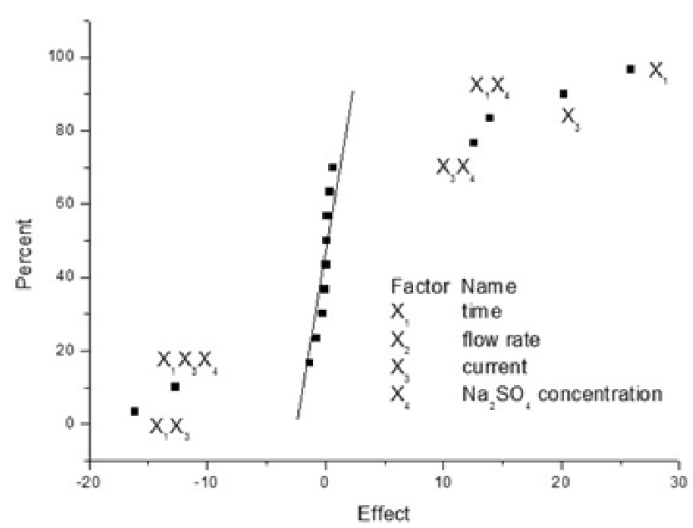

Figure 2. Normal probability plot of effects for degradation of bromophenol blue

The most common approach to identify the significance of effects is to construct the normal probability plot (Box et al. 1978). According to the results of
Table 3, the normal probability plot for each effect value was obtained in Figure 2.

Table 3. Average and main effects of the independent variables and their two and higher order interactions of the $2^{4}$ factorial design on the response factor $Y_{1}$

\begin{tabular}{ll}
\hline Effect & Effect Value \\
& $\mathrm{Y}_{1}$ (color removal) \\
\hline Average effect & 86.91 \\
Main effect & \\
$\mathrm{X}_{1}$ & 25.86 \\
$\mathrm{X}_{2}$ & 0.69 \\
$\mathrm{X}_{3}$ & 20.21 \\
$\mathrm{X}_{4}$ & -1.37 \\
Two-factor interactions & \\
$\mathrm{X}_{1} \cdot \mathrm{X}_{2}$ & 0.17 \\
$\mathrm{X}_{1} \cdot \mathrm{X}_{3}$ & -16.10 \\
$\mathrm{X}_{1} \cdot \mathrm{X}_{4}$ & 13.96 \\
$\mathrm{X}_{2} \cdot \mathrm{X}_{3}$ & -0.76 \\
$\mathrm{X}_{2} \cdot \mathrm{X}_{4}$ & -0.22 \\
$\mathrm{X}_{3} \cdot \mathrm{X}_{4}$ & 12.61 \\
Three-factor interactions & \\
$\mathrm{X}_{1} \cdot \mathrm{X}_{2} \cdot \mathrm{X}_{3}$ & 0.169 \\
$\mathrm{X}_{1} \cdot \mathrm{X} 2 \cdot \mathrm{X}_{4}$ & 0.09 \\
$\mathrm{X}_{1} \cdot \mathrm{X}_{3} \cdot \mathrm{X}_{4}$ & -12.69 \\
$\mathrm{X}_{2} \cdot \mathrm{X}_{3} \cdot \mathrm{X}_{4}$ & 0.39 \\
Four-factor interactions & \\
$\mathrm{X} 1 \cdot \mathrm{X} 2 \cdot \mathrm{X} 3 \cdot \mathrm{X} 4$ & -0.02 \\
Lenth's PSE & 0.59 \\
$\mathrm{ME}$ & 1.26 \\
$\mathrm{SME}$ & 2.48 \\
\hline & \\
& \\
\hline
\end{tabular}

As shown in Figure 2, treatment time $\left(\mathrm{X}_{1}\right)$ and applied current $\left(\mathrm{X}_{3}\right)$ had significant effects on degradation process. Furthermore, the degradation efficiency was influenced to some extent by test factors $X_{1} \cdot X_{3}$, $X_{1} \cdot X_{4}, X_{3} \cdot X_{4}$ and $X_{1} \cdot X_{3} \cdot X_{4}$. The other effects including flow rate $\left(\mathrm{X}_{2}\right)$ and Electrolyte concentration $\left(\mathrm{X}_{4}\right)$ appeared on a straight line, indicating the negligible impact on degradation performance.

Pareto chart was adopted to confirm the statistical importance of estimated effects. The Pareto chart displays the absolute values of all the effects in a bar chart, as well as the decision lines for ME and SME (Figure 3). 


\section{MATEC Web of Conferences}

In Figure 3 , six effects $\left(X_{1}, X_{3}, X_{1} \cdot X_{3}, X_{1} \cdot X_{4}\right.$, $\mathrm{X}_{3} \cdot \mathrm{X}_{4}$ and $\mathrm{X}_{1} \cdot \mathrm{X}_{3} \cdot \mathrm{X}_{4}$ ) were greater than the SME decision threshold, indicating the significance of these effects. $\mathrm{X}_{4}$ exceeded the ME but not the SME, which suggested that the electrolyte concentration in degradation needs to be handled with some caution. All of other effects whose value was lower than the ME could be considered to be negligible. These results were well correspondent with those obtained from Figure 2.

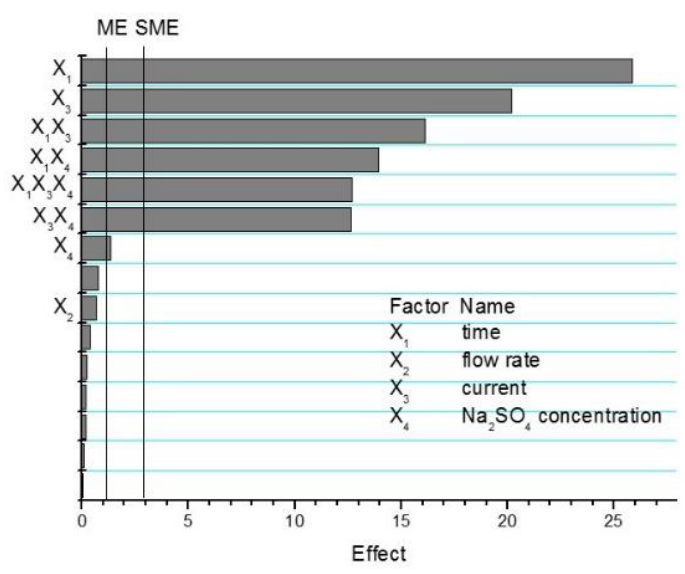

Figure 3. Pareto chart of the effects for degradation of bromophenol blue for the full $2^{4}$ factorial design

\subsection{Effect of test factors on COD removal}

COD removal rate is one of the most important indicators of sewage treatment. The COD values after degradation and corresponding COD removal rate were summarized in Table 4.

We used SPSS 17.0 to calculate the average effect, the main and the interaction effects all the same in this section. The results obtained in terms of response factor $\mathrm{Y}_{2}$, namely COD removal amount in $\mathrm{mg} / \mathrm{L}$, were presented in Table 5, in which PSE, ME and SME were respectively $20.05,39.43$ and 9.30 .

Figure 4 is the normal probability plot for each effect value on the basis of the results from Table 5. As shown in Figure 4, flow rate $\left(\mathrm{X}_{2}\right)$ and test factor $\mathrm{X}_{2} \mathrm{X}_{3}$ had great influence on the COD removal rate. In addition, the effect of treatment time $X_{1}$ and test factor $\mathrm{X}_{2} \cdot \mathrm{X}_{4}$ on COD removal rate should be considered to a certain extent. All other effects such as applied current $\left(\mathrm{X}_{3}\right)$ and Electrolyte concentration $\left(\mathrm{X}_{4}\right)$ that distributed near a straight line in Figure 4 demonstrated that they had very small effect on COD removal.

The Pareto chart of the effects for the COD removal as well as the decision lines for ME and SME was shown in Figure 5. As can be seen from the bar chart, the values of two effects (X2 and X2.X3) were larger than the SME, which suggested that the flow rate and $\mathrm{X} 2 \cdot \mathrm{X} 3$ played important roles in COD oxidation. The values of $\mathrm{X} 1$ (treatment time) and $\mathrm{X} 2 \cdot \mathrm{X} 4$ were be- tween the ME and the SME, which indicated that they should be paid attention in some circumstance. The values of all other effects were lower than the ME, revealing a negligible effect on COD removal. These results were well consistent with those deduced from Figure 4.

Table 4. Design matrix of the $2^{4}$ factorial experimental design and COD removal

\begin{tabular}{lllllll}
\hline Entry & $\mathrm{X}_{1}$ & $\mathrm{X}_{2}$ & $\mathrm{X}_{3}$ & $\mathrm{X}_{4}$ & $\begin{array}{l}\mathrm{COD}_{t} \\
(\mathrm{mg} / \mathrm{L})\end{array}$ & $\begin{array}{l}\mathrm{CRR} \\
(\%)\end{array}$ \\
\hline 1 & - & - & - & - & 79 & 23.9 \\
2 & + & - & - & - & 133 & 40.2 \\
3 & - & + & - & - & 121 & 3.7 \\
4 & + & + & - & - & 174 & 28.0 \\
5 & - & - & + & - & 147 & 9.4 \\
6 & + & - & + & - & 183 & 27.1 \\
7 & - & + & + & - & 173 & 27.5 \\
8 & + & + & + & - & 188 & 34.4 \\
9 & - & - & - & + & 102 & 30.8 \\
10 & + & - & - & + & 164 & 49.5 \\
11 & - & + & - & + & 143 & 3.6 \\
12 & + & + & - & + & 157 & 10.8 \\
13 & - & - & + & + & 180 & 27.4 \\
14 & + & - & + & + & 187 & 30.8 \\
15 & - & + & + & + & 163 & 49.2 \\
16 & + & + & + & + & 183 & 55.3 \\
\hline & & & & & &
\end{tabular}

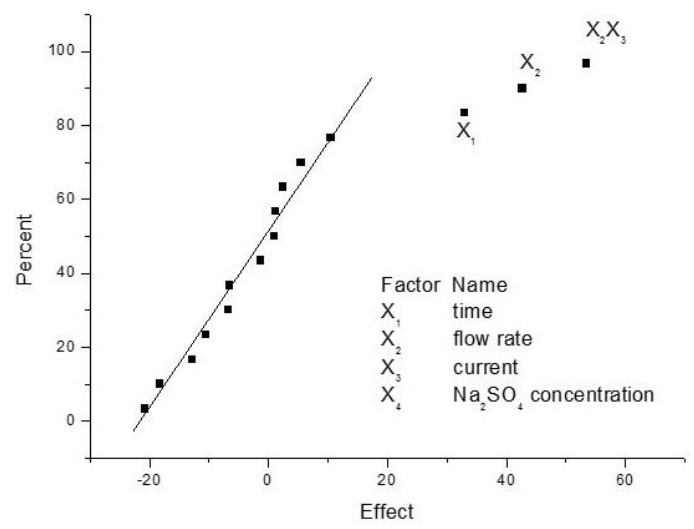

Figure 4. Normal probability plot of effects for COD removal 
Table 5. Average and main effects of the independent variables and their two and higher order interactions of the $2^{4}$ factorial design on the response factor $\mathrm{Y}_{2}$

\begin{tabular}{ll}
\hline Effect & Effect Value \\
& $\mathrm{Y}_{2}(\mathrm{COD}$ removal $)$ \\
\hline Average effect & 153.81 \\
Main effect & \\
$\mathrm{X}_{1}$ & 33.01 \\
$\mathrm{X}_{2}$ & -42.75 \\
$\mathrm{X}_{3}$ & -18.25 \\
$\mathrm{X}_{4}$ & 2.52 \\
Two-factor interactions & \\
$\mathrm{X}_{1} \cdot \mathrm{X}_{2}$ & -6.75 \\
$\mathrm{X}_{1} \cdot \mathrm{X}_{3}$ & -12.75 \\
$\mathrm{X}_{1} \cdot \mathrm{X}_{4}$ & -6.24 \\
$\mathrm{X}_{2} \cdot \mathrm{X}_{3}$ & 53.52 \\
$\mathrm{X}_{2} \cdot \mathrm{X}_{4}$ & -20.75 \\
$\mathrm{X}_{3} \cdot \mathrm{X}_{4}$ & 1.26 \\
Three-factor interactions & \\
$\mathrm{X}_{1} \cdot \mathrm{X}_{2} \cdot \mathrm{X}_{3}$ & 5.52 \\
$\mathrm{X}_{1} \cdot \mathrm{X}_{2} \cdot \mathrm{X}_{4}$ & -1.25 \\
$\mathrm{X}_{1} \cdot \mathrm{X}_{3} \cdot \mathrm{X}_{4}$ & -10.54 \\
$\mathrm{X}_{2} \cdot \mathrm{X}_{3} \cdot \mathrm{X}_{4}$ & 1.03 \\
Four-factor interactions & \\
$\mathrm{X}_{1} \cdot \mathrm{X}_{2} \cdot \mathrm{X}_{3} \cdot \mathrm{X}_{4}$ & 10.50 \\
Lenth's PSE & 9.30 \\
$\mathrm{ME}$ & 20.05 \\
$\mathrm{SME}$ & 39.43 \\
\hline & \\
\hline & \\
\hline & \\
\hline
\end{tabular}

\section{CONCLUSIONS}

This paper reports a detailed discussion on bromophenol blue on BDD electrode under a series of major operating parameters. A factorial design was employed to the optimization of experiment procedures. The effects of four test factors including treatment time, flow rate, applied current and electrolytes concentration on the performance of the process had been investigated. The results showed that the treatment performances were vastly influenced by the factor levels, and the effects of the various operating parameters on treatment efficiency were remarkably different. Thus the factorial design analysis of the various factors is of great use to the optimization of operating parameters and the practical application of this technology.

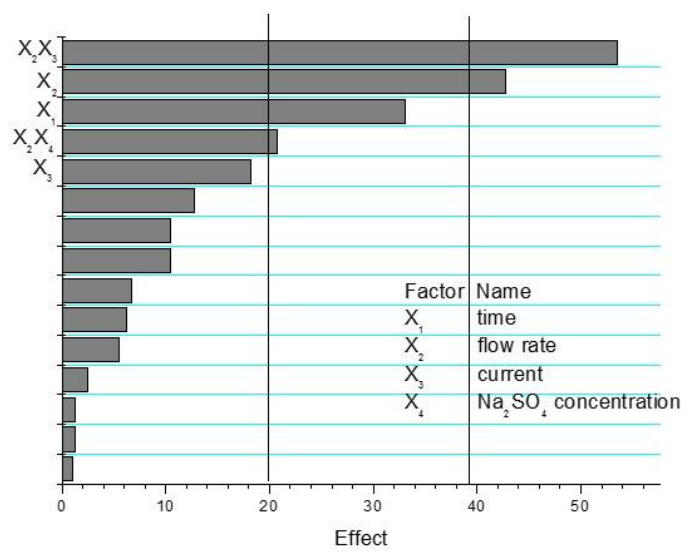

Figure 5. Pareto chart of the effects for COD removal for the full $2^{4}$ factorial design

\section{ACKNOWLEDGEMENT}

The work was financially supported by Natural Science Foundation of China (GN: 81202250), Sci-tech Development Program of Suzhou (GN: SYG201445), Social Developing Program of Jiangsu Province (BE2011797), Open Research Fund Program of Key Laboratory of Environmental Medicine and Engineering of Ministry of Education (Southeast University, No. 2010EME004), which are gratefully acknowledged.

\section{REFERENCES}

[1] Bouanimba, N. et al. 2011. Factors influencing the photocatalytic decolorization of Bromophenol blue in aqueous solution with different types of $\mathrm{TiO} 2$ as photocatalysts. Desalination. 275: 224-230.

[2] Box, G.E.P. et al. 1978. Statistics for Experimenters. New York: John Wiley and Sons.

[3] Brillas, E. et al. 2005. Mineralization of paracetamol in aqueous medium by anodic oxidation with a boron-doped diamond electrode. Chemsphere. 58:399-406.

[4] Cañizares, P. et al. 2005. Electrochemical oxidation of phenolic wastes with boron-doped diamond anodes. $\mathrm{Wa}$ ter Research. 39: 2687-2703.

[5] Fujishima, A. et al. 2000. TiO2 Photocatalysts and Diamond Electrodes. Electrochim Acta. 45: 4683-4690.

[6] Ghaedi, M. et al. 2014. Random forest model for removal of bromophenol blue using activated carbon obtained from Astragalus bisulcatus tree. J. Ind. Eng. Chem. 20: 1793-1803. 


\section{MATEC Web of Conferences}

[7] Hmani, E. et al. 2012. Electrochemical degradation of auramine-O dye at boron-doped diamond and lead dioxide electrodes. Diamond \& Related Materials. 30:1-8.

[8] Lenth, R. V. 1989. Quick and easy analysis of unreplicated factorials. Technometrics. 31: 469-473.

[9] Otto, M. 1998. Chemometrics: Statistics and Computer Applications in Analytical Chemistry. Weinheim: WILEY-VCH.

[10] Panizza, M. E. et al. 2008. Removal of color and COD from wastewater containing acid blue 22 by electrochemical oxidation. J Hazard Mater. 153(1/2): 83-88.

[11] Salem, A.I. 2000. Kinetics of the oxidative color removal and degradation of bromophenol blue with hydrogen peroxide catalyzed by copper (II)-supported alumina and zirconia. Appl. Catal. B Environ. 28:153-162.
[12] Sarma, S. \& Dutta, R. K. 2006. Electronic spectral behavior of bromophenol blue in oil in water microemulsions stabilized by sodium dodecyl sulfate and n-butanol. Spectrochim. Acta. 64:623-627.

[13] Szpyrkowicz, L. et al. 2005. Influence of anode material on electrochemical oxidation for the treatment of tannery wastewater. Water Res. 39:1601-1613.

[14] Torres, R. A. 2007. Bisphenol A mineralization by integrated utrasound-UV-iron (II) treatment. Environ $\mathrm{Sci}$ Tech. 41: 297-302.

[15] Vlyssides, A.G. et al. 2000. Electrochemical treatment of textile wastewater. Waste Management. 20: 569-574

[16]Zhang, C. et al. 2010. Anodic treatment of acrylic fiber manufacturing wastewater with boron-doped diamond electrode: A statistical approach. Chem. Eng. J. 161: 93-98. 